\title{
8. Asylums of Reason
}

A caseworker with whom I regularly exchanged was joking one day that he hoped I was not going to write an account of the office similar to that of "The Ship of Fools" [Das Narrenschiff], in which a former employee of a reception centre (located on a ship in Basel) denounced the practices of the office in the late 1980s (Graf 1990). I promised I would not - and I keep that promise. Obviously, as my account should make clear, the asylum office is neither well-captured by depicting it as a 'ship of fools' nor by considering it the 'last refuge of reason' (as ideals of bureaucratic administration as based on rational reason might suggest, see Weber 2009, 29). While I concur with insights from the anthropology of organisations that "bureaucratic rationality is 'bounded,' limited and flawed in its information, facing considerable unpredictability, and guided by past trial and error, lessons, and entrenched patterns" (Jiménez 2007, 493), I consider it important to go beyond this diagnostic statement and trace how considerations of officials are situated and composed of multiple rationalities.

In this chapter, I attend to the rationalities of caseworkers and their superiors for doing things the way they are done in the asylum office. By highlighting the diverging rationalities that sustain practices of case-making, I offer a reading of a dispositif whose enactment is fractured across different places and positionalities of accounting with ambiguous response-abilities (8.1). It moreover assembles divergent objects of government that affect cases' trajectories and resolutions in crucial ways (8.2). The spatiotemporal fragmentation of practices of case-making, the sometimes contradictory rationalities paired with experimentality, and a governmental regime entailing the creative searching for ever-new resolutions for all sorts of problems all lead to what I call "asylums of reason": patchy sanctuaries in which 'a certain reason' endures while other reasons are exteriorised (8.3). 


\subsection{Fragmented Reason}

I suggest that in order to understand both the composite reality of the asylum office and the many diverging forces, we need to be attentive to the material-discursive means of association that are able to compose perspectives and practice and to the material-discursive means of dissociation that set elements and perspectives apart. While the first line of enquiry highlights some of the possibilities and "plug ins" (Latour 2005, 207) of personal authorship (what difference can 'I' make?) this involves, the second line of enquiry traces positionalities of officials that appear in their accounts of bureaucratic Others. Certain differences of approaching processual events of case-making could be explained not only by officials' professional habitus (Affolter 2017, 2) - the internalised dispositions of how to do things developed on the job - but their habitus more generally (Bourdieu 1977). However, few people will be surprised that officials' personal biographies impact how they see and do things - that they have a "second body" beyond that institutionally prescribed (Miaz 2017, 360-61). Yet, to understand what impact such a "second body" has on perceptions and practices in the office remains a task worthwhile. Miaz (2017, 371-81), for instance, suggested a sociological differentiation of individual caseworkers in the Swiss asylum office that allows positioning them between the (emic) poles of rigid ("hardliners") and credulous ("softies"), and between output-oriented and meticulous. He moreover emphasised that most people tend to situate themselves somewhere in between these poles (as the extremes are somewhat stigmatised). Complementing such an analysis, I suggest that some of the differences in case-making, however, are associated with how caseworkers deal with the burdens and elations of casework (8.1.1) and with the fragmentation of ways of knowing and doing asylum as (de)stabilisations of the dispositif (8.1.2).

\subsubsection{Elations and Burdens of Caseworkers}

We just have to be a bit jurist and pastor and both in one at the hearings. (Interview with caseworker, autumn 2013)

In this section, I offer some threads of explanation for how caseworkers see their role and scope of making a difference concerning the cases they encounter. These threads could be read as related to a "professional habitus" 
(Affolter 2017,2$)$ that caseworkers develop and that allow them to understand the stakes of asylum case-making and their role in it. ${ }^{1}$ However, I am more interested here in the "bodily excitations and sensualities, powerful identifications, and unconscious desires of state officials" (Aretxaga 2003, 395) - how they feel about their work as asylum office collaborators and state representatives. Such feelings are arguably particularly marked in the asylum office since the matter of granting or rejecting of asylum is both highly politicised and fraught with moral burden (e.g. Fassin and Kobelinsky 2012). A wide range of feelings appeared in my observations of case-making: anger about "being lied to all the time", indifference about those "who just try it [to get asylum]", pity or impotence in cases applicants deserved help that is however considered beyond scope, thrill about both the unpredictability of encounters and the investigation to resolve the case, and respect for those who "perform well". Caseworkers may also have some degree of sympathy or contempt for those who do not deserve protection at all, excitement about seeing into others' lives, voyeurism in probing into their stories, gratitude for being born on the right side of the fence, elation for providing protection, making a difference as well as "compassion, admiration and esteem" (Kobelinsky 2015a, 173-79). I suggest that such feelings of officials can be read as an associative force that makes personal authorship possible. I consider personal authorship to be related to the feelings that caseworkers have about the difference they make in case-making. I thus limit myself for the purpose of this subchapter to feelings related to how caseworkers see their scope of authorship.

A first feeling that officials recurrently raised in my encounters with them concerns the associations with the outside. Many people in the office considered the outside view of the office as excessively negative and in need for revision. A statement of a senior official from the services division of the migration office in the basic training for novice caseworkers conveys this well:

The FOM is in the political line of fire like no other office; people think we are either too nice or too lazy or too strict - but we do a good job. There is barely

1 For such an analysis that elaborates what it means to be a 'good' decision-maker in the eyes of asylum office caseworkers and seniors, I point readers to Chapter 4 of Affolter's (2017) dissertation. 
an office in which you will find so many good and motivated people. Don't let yourself be buffaloed! (Fieldnotes, basic training for new caseworker, autumn 2012)

Since new caseworkers usually enter the asylum office 'from the outside', the senior official above reassured them that people on 'the outside' could not appreciate the "good job" they do. The discrepancy between the outside view of the office and 'actual reality' was a recurring issue in conversations with caseworkers. A caseworker whom I asked about her view of the office, for instance, told me about the surprise she felt that it was all better when seen from the inside:

I was actually positively surprised. I wasn't sure at the beginning how it would be. I couldn't really imagine something. And the FOM has to some extent a very bad reputation, a restrictive reputation. That's why I asked myself a little, who is working up there ${ }^{2}$ [laughs]. (Interview with caseworker, September 2013)

But there is more to the negative outside view of the asylum office that is revised once you've entered it. Another caseworker who had formerly worked as a legal representative said:

You know, when I said, I go to work in the FOM, everyone was like "hooooh, what, you're going to be one of those?" And I got the image myself, those are actually the bad guys. But in fact, everyone I met in the FOM is, yes, they're all very open. And you could say, you know, there are really good people among them who also want to help. And nobody is actually like "well, we have to deport them" or something. (Interview with caseworker, September 2013)

What these statements reveal is that caseworkers grapple with outside perspectives of the office that are, as the senior official above said, either "too nice" or "too strict". The office thus appears different, less black and white

2 This appears like a startling reference to the image of the state and those embodying it standing above society (Ferguson and Cupta 2002; Mitchell 2006) This hints at a second feeling: sentiments related to verticality (Ferguson and Cupta 2002), that is, associations of super- and subordination. 
from the inside, and those embodying the state a less homogenous mass than ascriptions from outside usually imply. ${ }^{3}$

Equally interesting is the idea that caseworkers want to help, which indicates a certain ethical impetus of persons working in the asylum office. The caseworker quoted above qualified this ethical impetus as follows:

As most people [working in the office] talk, you don't have the feeling that anyone has the intention to deport as many as possible or write as many negative decisions as possible, but just really make their work thoroughly and are also glad, glad if they once can write a positive [decision]. Just everyone who once started in the FOM actually rather comes from the side "I want to help", even if it maybe gets lost sometime, [laughs] after a while. (Interview with caseworker, autumn 2013)

She told me that she would "try to acquaint herself as well as possible" in the office. I was wondering what she considered the variations of how caseworkers (she knew) see their role. She said:

There are maybe people who do not care that much [about the ethics of casework], you know. Yet, I have to come to the defence of those who maybe are in situation, also personally, in which this does not matter so much. But they certainly do nothing wrong, but simply, lack of motivation, is maybe the proper word for it. (Interview with caseworker, autumn 2013)

There are, according to these statements, people working in the office that "want to help" and those who do not care too much. ${ }^{4}$ The perception that working in the office usually entailed some disillusionment seems moreover quite common. Caseworkers and superiors told me that working in the

3 As Gill (2010a) pointed out, it also matters for asylum activists' approaches to how they "imagine the state" - either as a homogeneous opponent or as a field of heterogeneous people with potential allies.

4 If you, in turn, talk to proponents of those "who do not care too much" in the view of the former, they will tell you that wanting to help creates more evil than good as it involves to "bend the rules" in individual cases and thus creates unequal treatment. For a more detailed discussion about the controversies of who is a "good decision-maker", see Affolter (2017, 81-106). For a typology of decision-makers in the asylum office, see Miaz (2017, 71-81). 
office transforms you and some of the sentiments you carried at the beginning wither, that you may start out with the aim "to help" and end up with a "lack of motivation". Yet, many of those I encountered pointed out that it was gratifying for them to know they were "able to make a difference". This ability to make a difference endows the 'I' with meaning:

Caseworker: And of course, it's nice and makes this work meaningful, if your realise, it was due to me in this case, like this...

Researcher: And I think it is something where you can make sort of a difference, right?

Caseworker: Yes, exactly.

(Interview with caseworker, summer 2013)

To be able to make a difference can, however, not be taken for granted. While both the right scope of associating practices with the 'I' and the possibilities for personal authorship remain deeply contested amongst caseworkers and seniors, their positionings could also change over time-space (with their career, with new posts).

Asked how they see their role in the whole procedure, caseworkers often told me variations of being "just a small cog in the works" (Interview with caseworker, autumn 2013). In her study of asylum officers in the UK, Jubany (2017, 74-75) witnessed a similar feeling amongst them of having no personal bearing. Unlike the officers in the UK, however, the caseworkers in the Swiss asylum office found this to be reassuring rather than frustrating, as they viewed it less as an expression of powerlessness than about sharing the burden of decision-making. But what to do about this seeming contradiction between caseworkers' appreciation of making a difference contrasted with making no difference? Does it express what Goethe's Faust poetically framed: "two souls, alas, are housed within my breast, and each will wrestle for the mastery there"? Indeed, I sensed "two souls were housed in the breast" of most caseworkers I met. The feeling of personally making a difference accords meaning to their work (which seems to be lacking in many other forms of bureaucratic work; see Graeber 2014). In contrast, seeing themselves as not making a difference discharges then from the moral weight of their work: if anyone else could have done it instead of them, they did not have to account for why they did it that way. In the most extreme versions I encountered, caseworkers negated having any 'real discretion' in their work, 
such as this caseworker in the reception centre who told me about his current cases and, at some point, himself broached the topic of discretion:

I don't have a bad conscience because I do not have real discretion anyways. If you take the paperlessness article, there it's clear that the legislator wanted to set a legal bar that certain applicants cannot enter the normal procedure and there I don't have any leeway. Sure, I could ask here and there a bit less [in the hearings]. (Fieldnotes, reception centre, spring 2013)

This statement echoes a senior official who taught the module on DAWES or non-admissibility decisions in the basic training I attended: "Non-admissibility decisions [DAWES] do not have a 'may'-wording [Kann-Formulierung] [in the Asylum Act]: this means if a committed act [Tatbestand] falls within their terms, a non-admissibility decision* must be taken" (Fieldnotes, basic training, 2012). Admittedly, the scope is largest with legal provisions that have a "may"-wording, yet I would still object here that to figure out whether "a committed act" falls within non-admissibility terms still always requires interpretation. ${ }^{5}$

Yet, the caseworker in the quote above moreover directly relates not having 'real discretion' to not having "a bad conscience", thus indicating that caseworkers fear 'real discretion' for the moral conflicts associated with it that become personal ones, if one feels able to make a difference. A common solution, it appeared to me, is therefore to acknowledge that one can occasionally make a difference by granting protection against institutional odds while usually clinging to "what you have to do" (see also Affolter 2017).

Not having to account for a case as an author was thus usually associated with a state of relief. But not always: it can also be negatively associated with a feeling of impotence, if it relates to the absence or lack of authorship that one would like to have in a particular case.

5 Moreover, as I tried to demonstrate in Part II, it also requires the necessary material-discursive associations to authenticate the claim (such as trusted assertions, documentary or bodily 'evidence', case law or reports), to argue with in a decision* (such as boilerplates and tick boxes) and an 'intimate conviction' about the merit of mobilising such associations (see also subchapter 7.1). 
Researcher: Is there a case you can remember well from this first year of working in the office?

Caseworker: Well, one case was that of a minor [female]. And with a child, yes, she had the child already. And she was in Belgium first. They have quite a good system for minors there, particularly for minor mothers. However, she has been threatened there by the father of the child. And I really believed this. But then, she had a fingerprint hit and all. Nevertheless, I tried with the Dublin office, back and forth, whether there was no possibility of self-admission [Selbsteintritt], for such a young mother, right? There should be a possibility... No chance! And this is what, I think, stresses me most. If you have to send people back, particularly to Italy... And if you know, it's actually against your own principle.

(Interview with caseworker, autumn 2013)

Caseworkers curiously appeared to care more in cases people were sent back into what they considered difficult or unbearable conditions in Dublin states than to the (often worse) conditions in their home countries. Does the latter involve an impossible imaginative leap? Maybe, but rather I think they are not feeling responsible for those conditions far away. Besides, people lived under these conditions before they fled. In contrast, the Dublin system was considered unfair in general and somehow 'our' system. Thus, enacting it makes many caseworkers feel complicit in reproducing this unfairness.

Interestingly, the management of the asylum office did nothing to resolve this ambivalence. Already in the basic training for new caseworkers, the module teacher (a senior official) told my co-participants and me, "You are responsible [for the decision], you signed it." Later on, he called this again in question by saying: "the responsibility is with you: I told you before and nobody objected. Well, but the superior signs it [the decision] too" (Fieldnotes, basic training for new caseworkers, autumn 2012). But he did not explicate what this means for caseworkers' responsibility. Far from removing the ambivalence about one's scope in case-making, I suggest that statements like this rather accentuated it.

Overall, the discursive framings of work in the asylum dispositif often seem to be limiting the associations for which one is able - or willing - to take personal authorship: the 'I' is thus not only assembled with various devices for "collective authorship" (see Chapter 5) that limit its scope for personal authorship. It is equally - and relatedly - the limit personal agency 
caseworker attribute to themselves. While collective authorship thus prevails, the cases in which caseworkers have a sense of their personal authorship are nevertheless crucial for giving meaning to their work.

\subsubsection{Schools of Practice - Reasons of 'Style'?}

In this section, I suggest that the asylum office is not only heterogeneous in its composition, but that it tends to multiply in time and in space: its subdivisions develop 'insular' practices with their temporal scope. While a certain insularity in perspective and practice is not so surprising for the reception centres that are spatially dispersed, I would have expected it to be less marked in the headquarters of the office in Bern. The peak of dissociation between parts of the headquarters of the asylum office was arguably at the time that country teams existed (see section 4.1.3).

People in the office often referred to different "schools of practice" as well as "styles of decision-making". New caseworkers were already "warned" in the basic training I attended that different practices may exist in the sections, that superiors each have "their own style". But the senior official teaching the training session was quick to specify that the differences in practice concerned only matters of discretion, typically foreseen by the legislator in "may"-regulations. Yet, as I have suggested in Chapter 7, pronounced and sometimes diverging convictions exist about much more than "may"-regulations - basically about any central notion and technique on which a procedure is based.

In a piece written together with Affolter and Miaz (2018), we discuss the fragmentation of the office and its consequences for what 'just' decision-making means for different "communities of interpretation". ${ }^{6}$ We suggest that such "communities of interpretation evolve along the fissures between sections, divisions, professions, experience, and hierarchy" (ibid., 276). Without reiterating the discussion here, I briefly indicate some of these fissures in order to support my argument that dissociations in seeing and enacting the dispositif exist. The initial quote has suggested that developing

\footnotetext{
6 This term "communities of interpretation" emphasises the convergence of interpretations of approaches to decision-making, one's role, and notions of justice in subsections of the office. Conceptually, it relates to both Wenger's (2003) notion of "communities of practice" and Yanow's (2003a) "communities of meaning".
} 
one's own style is a feature of the past. While differences in 'style' maybe have been even more marked in the past, they are still very prevalent, according to what I heard and saw in the office. They become visible in accounts of officials' accounts of bureaucratic Others (see Said 2009). And they contribute to fragmented practices and positionalities - each cultivating their own rationalities about governing asylum.

What I suggest here is that differences in case-making arise from distinct ways of knowing and doing things and are explained with certain rationalities in different sites of the office. For instance, heads of sections in the headquarters are advocates of different modes of assigning cases to 'their' caseworkers, as this quote of a caseworker indicates:

I make a personal attribution of cases [to caseworkers] - but very different opinions about this prevail in the office. I am rather an advocate of specialisation, which means that caseworkers are specialists for certain topics and countries. Others regard a generalist approach [Generalistentum] to be superior: if everyone does everything. That's been like this since I have been heresince 1994. At times the former come out on top, at times the latter. (Fieldnotes, headquarters, spring 2014)

Thus, over time, either the generalist approach or the specialist approach becomes the 'normal' one, and the other requires justification to be upheld. How cases are assigned to caseworkers (see subchapter 6.3) thus not only is dependent on the practical knowledge seniors acquire, but also on the 'school of practice' a certain head of section belongs to. The two sections in the headquarters in which I did field research belonged to different schools concerning how they introduced novice caseworkers to their work. One section was a so-called "tourist section" in which "everyone has to first learn the law and then gets a case file to go through". In the other section, the principle is "everyone does everything", and people jump in to learn casework by doing (Fieldnotes, headquarters, spring 2014).

Many organisational features of case-making appeared to be locally established - and may be justified with rationales contradicting the ways in which things were done in other places. A good example of this is how first and second hearings are organised in the reception centres. In the centre where I had done my fieldwork, it was clear that, if possible, the same person would conduct both hearings, as that person would already know the case. I 
was thus quite surprised when I learned that in another reception centre, the opposite was standard. A caseworker from the latter centre told me, "We look that never the same person conducts the first and the main hearing, because this is very unpleasant. If you have to talk to this same person twice and they look at you with large eyes and say, 'but I have told you everything about it before"' (Interview with caseworker, autumn 2013). 'Good' reasons for different approaches exist - yet only the one I had become familiar with in the reception centre I had been 'socialised' in made sense to me. Some of these differences between 'standard approaches' are well known - and are even sometimes jokingly raised by caseworkers. Others seemed to be little known.

For caseworkers, certain approaches require justification, as they represent a deviation from the 'normal' solution. A caseworker, for instance, told me about the shift in what approach to credibility was considered standard between his former and his current team (after the reorganisation):

In my old section, there were mainly older, experienced caseworkers who assessed everything as 'not credible'. The context makes an extreme difference: now I am in a section where I have to justify myself rather if I make a negative one [decision]. [Others ask:] 'Are you sure that this is 'not credible'?' Formerly, [it was] the same for the positive ones. (Fieldnotes, headquarters, winter 2013/14)

What this quote indicates is that, for caseworkers, employing certain associations to resolve cases appears normal - but what is common for them might not be considered normal in other sections of the office and in different times. Interestingly, as the office went through a series of reorganisations and caseworkers had to apply to 'new' sections where only the heads of sections had been appointed, they usually chose a head of section with a similar notion of 'normalcy'. This led to a certain convergence of 'views' inside the sections and arguably increased the divergence between the sections. I do not want to imply that sections became homogeneous; only that a certain tendency towards homogenisation seems to have accompanied the reorganisation I witnessed. ${ }^{7}$ A caseworker from a reception centre told me:

7 This observation mainly concerns the sections in the headquarters. I do not know whether it also occurred in the larger reception centres where the leadership span was reduced and thus new sections emerged. 
We now have two teams [since the reorganisation]: a young and an old one. Everyone had to newly apply in the course of the reorganisation, and one of the heads is not very popular. Those who indicated in the motivation letterbetween the lines - that they do not want to be with her, are now in the young team. Who didn't care or indicate any preference is now in the 'residual team'. (Interview with caseworker, reception centre, autumn 2013)

Some caseworkers regretted that the office's 'social fabric' had been shattered by the recurrent (and as most people thought) not well-devised reorganisations. An interpreter whom I accidently met on the train home from the reception centre told me:

I was in Wabern [the headquarters] yesterday. There I talked to a caseworker who is a long-term employee and a positive person. He was really annoyed about the [current] reorganisation: they would slash everything with it in the headquarters in Bern, the whole social structure was destroyed. He said that this had started under [Federal Councilor] Blocher and continued under Widmer-Schlumpf. The latter for instance sacked the vice-head of the office to hire him again the next day. There's again a huge chaos in the office and nobody knows exactly what and where. (Fieldnotes, on the train, spring 2013)

Similarly, a long-term caseworker I met in the reception centre told me that she had largely withdrawn from the "institutional facets" in the office and now just did her job: "One tends to withdraw from these whole institutional facets if one has experienced such radical changes too often. It is difficult to see how co-workers with whom you have built a social relationship are laid off from one day to the next, as this has been the case here" (Fieldnotes, reception centre, spring 2013). But while such reorganisations tend to destroy the 'social fabric' of the office and are seen very critical by most of those who went through more than one, they also offer opportunities for some. I met a few relatively young and recent employees who were promoted in the course of these marked institutional transformations. One caseworker with whom I had attended the basic training for new caseworkers told me when we met about a year later for an interview outside the office, "I was already promoted. In the course of the reorganisation, I could take over the post of a specialist section vice-head" (Interview, former caseworker, autumn 2013). And he was not the only example for such quick advancement in the admin- 
istration. But such recurrent re-compositions of teams and reshuffling of hierarchies were an additional source for the fragmentation of practices and the development of dissociated 'styles' of case-making. It is important to note that even though reorganisations may have caused "huge chaos in the office", it is exactly the many associations of case-making stabilised in the material-discursive arrangement of the dispositif that were not touched by the reorganisation (see Chapters 4-5) and secured its further operation (despite apparent chaos and staff turnover).

The heterogeneity of practices and perspectives seemed to trouble the caseworkers themselves and they often related it to a notion of inconsistency. The 'pre-set value' of credibility assessments, for example, was often associated with the duration of working in the institution (the longer inside the less people tend to believe the stories), or ethical-political stances of protecting asylum seekers versus protecting the nation (see also Affolter 2017). New caseworkers are usually more closely monitored in their work, whereas oversight decreases with experience and "independent work" begins, as a caseworker after her first year in the office contentedly stated on my question whether she liked to work in there:

Yes, now the independent work begins, that's quite nice. - That you are less dependent on others? - Yes, and that you don't always have to ask. And maybe you are also more courageous. You simply try things. If it's not correct, someone is probably going to tell you at some point." (Interview with caseworker, reception centre, autumn 2013)

Doing things more independently was often equated in the office with developing one's own style. Even though there seems to be an obvious tension between independence and consistency, both rationalities were highly valued.

What moreover contributes to the development of different 'styles' of organising and approaching things is that knowing in the office appears to be severely fragmented. A recurrent criticism from caseworkers and their superiors directed at the management concerned the sharing of know-how or transfer of knowledge: between the sections doing the same work (the different reception centres and the sections of the headquarters) as well as between the different locales of case-making. One caseworker, for instance, said: "The knowledge transfer works really very bad in the office. Maybe [it is] because 
they [the management] always reorganise everything. Many things need to be written down in this process, pile up, and get lost" (Interview with caseworker, reception centre, autumn 2013).

Since the management seems inclined to "always reorganise everything", knowing the current state of affairs in all domains becomes almost impossible. This quote indicates the crucial role of coordination devices - and their absence making coherent practices difficult. What caseworkers and heads of sections mentioned often to be missing was a database for the exchange of written decisions" beyond sections. The sections each had their file repositories on the server. But even though in the headquarters, one could access the repositories of other sections, they were organised and handled differently. And from the reception centres, these repositories were not accessible at all. The head of the centre said, "The knowledge management in the FOM is a catastrophe. Provincial thinking prevails: everyone files the documents nicely for themselves. There is no common database" (Fieldnotes, reception centre, spring 2013). Yet, nobody seemed to know why no proper database for sharing decisions" existed. One might also ask the reverse question: what does a certain provincialism or fragmentation in knowing and sharing know-how offer in the view of those in the higher echelons of the office, who could introduce such a database?

\subsubsection{The 'Dark Forces' are the Others}

I sometimes have the feeling that there are some dark forces in the headquarters which want to produce negative decisions no matter whether the arguments for this exist or not. (Fieldnotes, reception centre, spring 2013)

The asylum dispositif, on closer inspection, appears fissured - in all of its locales lurk forceful Others that threaten one's work or even 'the system'. The 'dark forces' are always these somewhat opaque Others - which are thus constitutive of the identification with a particular 'community' in the office (see Said 2009). For those in the reception centres: it is the headquarters; for those in the headquarters: the reception centres; for the newcomers: the long-term employees; for the long-term employees: the newcomers; and for the subordinates: the superiors, the management; and so on. While these internal fissures are not very surprising, they are important for the development of positionalities inside the office - everyone has associations with 
some parts of it, and dissociations from other parts. Of course, these are very generalised fissures and nobody I talked to would draw them all too firmly. Caseworkers and superiors develop their positionalities in relation to more than one 'community' and these are not static either. Most know people from other 'communities' they respect or even admire. However, these fissures still matter to the extent that they indicate the limits of certain "communities of interpretation" (Affolter, Miaz, and Pörtner 2018) of case-making. And through their enactment on many occasions - in meetings, discussions, interviews with me - they become relevant associations for trajectories and outcomes of cases-in-the-making, which makes them worth tracing. A simple explanation for the frequent reference made to these fissures would be to take them as an effect of 'leaving someone else holding the baby' [jemandem den Schwarzen Peter zuschieben] in case things go awry. However, at a second look, they are better understood as an effect of divergent positionalities in case-making that shape the vantage point on cases' assembling and resolution. The reactions a delegation from the headquarters sparked in the reception centre exemplify this.

I attended an info meeting of a delegation from the headquarters that presented a new 48-hour procedure for Ukrainian cases and additionally provided country of origin information on Ukraine. After the meeting everyone leaves the room quite quickly. Nobody seems to seek the dialogue with the people from Bern [the headquarters]. The latter have to continue their journey to Vallorbe where they have the same presentation this afternoon. A senior official is already standing outside the building, smoking with a caseworker. I join them. She says "this is again a hasty reaction from Bern [the headquarters] with the 48-hour procedure for Ukraine, not thought out. If three reception centres - [names] - cannot enforce [removals], then this does not solve any problems. But in Bern ... this is the favourite recipe: since it has worked so well with the Roma, ${ }^{8}$ one wants to do the same with more and more others too. But this is comparing apples to oranges. Besides, I don't like if Bern decides on our capacities here: with the 48-hour procedure and pre-drawing them at the BSM (border sanitary measures), this takes time

8 Such 48-hour procedures were first introduced for Roma from European "safe countries" such as Bosnia-Herzegovina, Serbia, or Hungary (see also SEM 2012). 
and effort for assignment and hampers optimal utilisation of resources". (Fieldnotes, reception centre, spring 2013)

In the view of the senior official, the new procedure in this case 'does not solve any problems'. From her perspective, people in the headquarters lack an understanding of how things relate in case-making for them here. Furthermore, she does not like the headquarters threatening the independence of the centre in organising processual events of case-making according to its own rationalities. In turn, between the lines, the protest about this new procedure to be introduced is also an expression of their dependence on arrangements being remade in the headquarters. In the headquarters, in turn, reception centres were sometimes considered as somewhat obstinate and capricious in their approach to case-making.

A specific case of a homosexual man from Uganda illustrates this well, as I encountered it both in the reception centre and later in a section in the headquarters. A reading of this case-in-the-making I encountered in these two different localities on three occasions illustrates how the vantage point on cases and rationalities concerning their reading occasionally differs between the reception centres and the headquarters. In the reception centre, the case had a specific history with several layers: a first and a second application that were accompanied by several encounters with the applicant. The caseworker in charge of the case and his superior were convinced that the applicant's grounds were a fraud. Besides the fact that the applicant had introduced homosexuality as a ground for persecution only in the second application, the caseworker and his superior felt it was not that clear that he would really be threatened upon return - and questioned whether this was actually applicable in the country of origin information indicated. For them, this case appeared to be an exemplar of abusive second applications that they frequently encounter (much more often than the headquarters). Since they considered the claim not credible, it did not matter to them so much what the office's practice* of gender-related persecution was or what COI stated about the "situation of homosexuals" in Uganda (see Figure 7, section 5.2.2). They were determined to write another decision* of non-admission (DAWES) and see how the court would evaluate it.

I came across the case in the headquarters about nine months later. Here it had, in contrast, no history. But the section of the senior official who encountered the case in passing had developed a new practice* on gen- 
der-related persecution (see section 7.2.3) according to which the case which he felt "was clearly positive". Yet, people in headquarters could not force the reception centre to pass the case on to them for resolution. They were just occasionally reminded of its existence, when new submissions arrived at the office concerning the case. And they could mock the reception centre for an overly personal involvement in cases ('having a score to settle') and shirtsleeved or "rush rush"-approach to case-making (see also Affolter 2017; Affolter, Miaz, and Pörtner 2018). Thus, the different perspectives on this case reveal that previous associations of case-making matter for how it is viewed; and that both 'sides' - the reception centre as well as the headquarters - are suspicious of the case's evaluation by the internal Other.

But such fissures also exist between the different reception centres and between the divisions and the sections in the headquarters. For instance, one reception centre is well-known in the whole office to be "the most rigid reception centre"; and in the headquarters, one division with four sections was more markedly affected by the 'government by number approach' than the other division (see section 8.2.2). Hence, it appears that - as in the frictions between the headquarters and reception centre - the strong association and reliance on each other fosters antagonism at time. But on the other hand, one also respects the Other and knows that one fundamentally depends on each other in the wider division of labour across processual events of case-making.

As I suggested in this chapter, we end up with heterogeneous assemblies that are enacting the asylum dispositifacross different interfaces of case-making. While they are associated through a range of rationalities and technologies, they are also dissociated in crucial ways: for those working in the office, the resulting fragmentation of the office explains some of the differences in case-making (beyond "individual differences"). The different ways of doing and seeing things stand moreover in tension with each other and the contestations around the 'right' approach keep the dispositif in motion.

\subsubsection{Response-Abilities?}

It is a fact that the work process [in the asylum office] characterised by a marked division of labour and hierarchy fragments the individual moral responsibility of FOM collaborators for their actions and thereby undermines 
it. Adding to this, the hierarchical principle leads in the FOM - as it is typical for administrations - to the tendency to delegate the responsibility for delicate decisions upwards and thus hedge one's own actions through superiors. ${ }^{9}$ (Parak 2009, 4)

Administrations appear to have a troubled relationship with the humans populating them. Officials are becoming equipped to "speak in the name of the state" (Gupta, 1995, see also subchapter 5.1) but are supposed to personally fade for the administrative practice to appear disinterested, consistent and objective (Weber 2009). Excess in the fading of the human face and ethics of administrations, however, is viewed as problematic since it leads to "indifferent" bureaucrats (Herzfeld 1992) and the inhuman treatment of people encountering them (Lipsky 2010). In turn, bureaucratic organisations also have a problem with (overly) interested and engaged officials as their practices are considered to move into the realm of politics and thus subvert administrations' "neutrality" (see du Gay 2009). However, debates about the ethos of officials also touch on discretion and responsibility in a diagnostic manner that I consider rather unpromising. They often revolve around the question of degree: how much discretion and thus responsibility do bureaucrats have? Or they may even take a binary form to ask: are bureaucrats acting responsibly and/or held responsible or not? In contrast to such accounts, I suggest to attend to the sense-making endeavours of officials and engage with their own reflections and critique.

I suggest to go beyond the image that responsibility in organisations is simply delegated to superiors, as Parak (2009), the quality manager of the SEM, suggested in the quote above; or that it is worn away beyond recognition since it is endlessly distributed, moved up and down, as Eule (2013) argues in the case of German migration offices. What often seems the problem with responsibility is that no distinction is made between the discourse of responsibility, or 'attributable responsibility', and practices of responsibility or what I call 'response-ability'. The former is indeed delegated and may circulate and lurk in the dark to resurrect and hit someone unexpectedly, or it might be altogether fleeting (Eule 2013). It appears momentarily at particular events of overflowing in which the discourse of responsibility is raised and attribution asked for (see for instance the case of Van Tha, section 7.3.1).

9 Own translation from Cerman. 
This is the common, normative form of responsibility usually invoked. The latter, pragmatic form of responsibility evolves in everyday practices that are considered part of a collective undertaking. It does not need to be uttered - it rather takes the self-reflexive form of bringing own ethical considerations in tune with expectations of others (what Wenger 2003, 79, called "alignment" in communities of practice) but also with those of oneself. It is about (silently) answering questions such as: does this letter satisfy the expectations of my superior? Is the subsequent caseworker able to write a decision" based on the hearing protocol I produced? Do I do justice to the applicant with this kind of decision? It is thus multi-layered and open-ended in the weighting of the different questions. It is closer to a situated accountability - again as the ability to give an account of something or someone in a particular encounter - than the abstract, generic responsibility. I suggest to rather ask: whom or what are caseworkers and senior officials responsible for; and what account would they give to explain their action - what are their pragmatic instead of abstract virtues (MacIntyre 1984) $?^{10} \mathrm{I}$ thus suggest a shift in perspective to avert simple conclusions such as that ethics in bureaucratic settings are defective or that bureaucrats are indifferent. ${ }^{11}$ Attending to officials' reflections about their work can reveal how particular governmental arrangements and occupational roles crucially impact the answer of officials to the question: "of what story or stories do I find myself a part?" (MacIntyre 1984, 216). It can reveal the rationalities and convictions of officials emerging from the need to cope with stress, contradictory requirements and moral burdens related to their job - and their at times problematic effects.

This raises a question about the accountability of those scripting applicants' accounts and those writing the account that comes to matter, the asylum decision", who are writing themselves vastly out of this account and can "hide behind the law", as a caseworker in an interview aptly said (see section 7.2.1): Whom are the officials in the asylum office actually representing, who

10 This could also shift the discourse in the literature on the state and bureaucracies away from the notion of "corruption" (particularly in the global South; see, for instance, Chatterjee 2011). Corruption implies that bureaucrats are irresponsible, unaccountable in their work without asking about their pragmatic virtues. That's also the reason why corruption arguably only exists at a diagnostic distance - it only works as a condemnation, not as an explanation.

11 For instance, the indifference of Creek bureaucrats regarding citizens' concerns that Herzfeld (1992) noticed. 
do they speak and write for, if not for themselves? Importantly, the "structure of address" (Butler 2005, 39) in which caseworker give an account of themselves does not foreground the applicants, but the seniors who authorise their accounts and take some of their weight but also evaluate their numerical output. In these accounts, considerations may include their own unwarranted labour relations: the bulk of newly hired caseworkers receive only temporary contracts during the first three years in the asylum office. The addressees of the accounts they write most often - decisions" - are not primarily applicants either. To be sure, applicants have to be notified about the decision", but the account has not to withstand their judgement but that of the appeal court. Hence, the dispositif of governing asylum encompasses an administrative politics that entails a whole bundle of dissociations from applicants in practices of case-making. What stands between applicants and caseworkers are in effect two highly uneven spheres of account-ability. Claimants' accounts about themselves are heavily mediated by the rationalities and technologies of recording and inscription (see subchapters 5.2 and 6.2). Caseworkers in turn are polyphonic in their accounts - they speak (at least) in 'voices' of the law, the truth, and the numbers. Becker (2001, 197) argued that officials "disinterested engagement and intimate distance" have been crucial for their double role of speaking to applicants in the name of the state and of its citizenry: "Intimacy and engagement were part of their role in protecting the commonweal and its citizens, and, as officials, they were exclusively engaged in the case and in the efforts that were necessary for its solution" (Becker 2001, 197-98). Such a reading acknowledges that caseworkers have multiple positionalities to enact and ambiguities to embody. It can thus account for some of the seemingly paradoxical stances caseworkers display towards the people they encounter and whose cases they have to resolve.

\subsection{The Government of What?}

One of the surprises of my field research was the insight that governing asylum is about much more than resolving individual cases. At a closer look, I started to realise that the objects of government multiply and take efforts in the asylum office into different directions. The first and most obvious object of government is certainly cases to be resolved: as applications to be processed and decided as instances of the legal. But the asylum disposi- 
tif has at least two other crucial objects of government: the second is number - quantities of (certain categories of) cases as backlogs to be reduced, quantitative counting of (parts of) case-making related to output goals and personal benchmarks to be reached. The third object of government is cases' anticipated effect: each case seems to be considered as involved in producing an effect. Cases in which asylum is granted are, for instance, considered to produce a so-called "pull effect". This means more applications of the same category are to be expected in the future. These three different objects of government are each (mainly) associated with a specific rationality: a legal rationality (of the rule of law and examining an individuals' eligibility to protection), an administrative rationality (efficiency and 'non-bureaucratic' processing), and a nation-state rationality (of security and biopolitics). As I have already traced various appearances of the legal rationality - which is pervasive in processual events of case-making (Part II) - and discussed convictions related to law as both a technology and rationality of government (Chapter 7), I will focus here on the 'non-legal' rationalities crucially affecting case-making: productivity (8.2.2) and deterrence (8.2.3). Both of them are crucially related to "centres of calculation" (Latour 2005, 178), which I will outline first (8.2.1).

\subsubsection{Centres of Calculation: Measuring and Forecasting}

In fact, from inside the system, the algorithms and mathematical formulae by which the world becomes to be assessed become, ultimately, not just measures of value, but the source of value itself. (Graeber 2014, 41)

The management board of the asylum office has an almost impossible task: it has to get the numbers right. But the number of asylum applications is volatile like no other type of application. And the administrative workforce cannot be rapidly adapted to different input numbers. ${ }^{12}$ The management board therefore faces the risk of both quickly increasing backlogs of cases

12 It cannot simply be increased because (in times of widespread budget cuts in the Federal Administration) the parliament has to approve the budget for staff increase. And if it is increased, new caseworkers have to be trained and it takes - as senior officials estimated-four to six months to become able to work productively and one to two years for them to become "fully productive" and capable of processing complex cases. This already indicates why staff decrease is an equally difficult and potentially momentous move. 
and idle personnel, if the ratio between 'input' and 'output' is out of balance. Against this backdrop, nobody will be surprised that statistics appear to be the management's preferred perspective for formatting the work performed in the asylum office. They have instated "centres of calculation" (Latour 2005, 178) to account for the organisational performance in numerical terms and to forecast future applications and thus workload. I confine myself in this section to the "metrological regime" (Barry 2002, 273; see also Latour 2005) of rendering case-making countable in numerical terms and therefore calculable. This has arguably crucial effects on case-making: as Barry (2002, 277) pointed out, "metrology puts new objects into circulation" and has both "performative and regulative consequences". I trace these objects and consequences in the case of the asylum dispositif.

In "centres of calculation" (Latour 2005, 178-81), sophisticated statistics of indicators on various levels of aggregation are produced, which provide those in the executive floors, but also the individual caseworker with a partial yet powerful re-presentation of the work expected, on-going and accomplished, of the composition of applications and their resolutions. Crucial for the equation is obviously the ratio between inputs and outputs: the management has developed for both inputs and outputs technologies and devices to measure and forecast them - but also to influence them in numerical terms.

\section{Measuring and Forecasting Applications: Input}

The measurement of asylum applications appears quite straightforward: it consists of the counting of numbers of applications in receptions centres (and the airports) and indicating the type of application. In one of the sections where I did my fieldwork, an excel file with the weekly applications filed was forwarded to all staff by the head of section. For the headquarters, these numbers allowed for an immediate update of both caseload and the more difficult predictions of future applications. Such foresight and planning were highly relevant for heads of sections and caseworkers. For instance, case files have to be sent to the SAM - the service division of the asylum office organising the hearings - usually three weeks in advance to hearings. Case files of some categories and 'critical' countries of origin need to be referred to the Federal Intelligence Service (FIS) for a check ideally before the main hearing, certainly before the decision. This evaluation can also take some days or sometimes weeks. 
In a monthly updated series available on the intranet entitled "Management Cockpit" [Führungscockpit], both the latest developments of asylum applications in Switzerland and European countries were gathered and compared in numbers and graphs, was well as predictions on the numbers and distribution of future applications. Such predictions can be surprisingly accurate for reasons outside the scope Swiss administration and politics, but more often fail for the very same reasons: too many unknowns play into the equation. The factors range from shifts in geopolitical constellations (e.g. the instability of Libya after the fall of Gadhafi's regime or the outbreak and fuelling of an increasingly internationalised civil war in Syria) to changes in escape routes of those seeking refuge and asylum policies of other countries. Together, such factors can lead to sometimes dramatic and relatively short-term changes in the numbers of asylum applications in a single country. Nonetheless, forecasting seems to be so deeply entwined with government that the absence of forecasts would probably raise more concern than attempts to forecast something as unpredictable as future asylum applications. What appears important is to maintain a privileged position in relation to the 'production facilities of knowledge' vis-à-vis the public, which is offered asylum statistics in monthly and national aggregates already 'digested' by the public administration.

\section{Measuring and Forecasting Productivity: Output}

Much more predictable are the numbers at the other end: regarding output. New Public Management (NPM) reforms, which emphasise "efficiency" and "effectiveness" as key foci in the management of public authorities, have been introduced in the Swiss Federal Administration since the early 2000s. In the wake of organisational reformation, NPM principles also entered the Federal Office for Migration (FOM) and led to a considerable shift in orientations. Probst (2012) observed a similar development in the asylum administrations in France (OFPRA) and Germany (BAMF), and Dahlvik (2014) in Austria (FAO). While productivity targets have become widespread, the NPM concept of "client-orientation" seems largely absent from asylum administrations (Probst 2012, 219). As Shore and Wright $(2011,3)$ noted, "the introduction of the principles and techniques of New Public Management (NPM) into local authorities, government ministries, hospitals, schools and universities has profoundly modified the behaviour and self-understandings of these organisations and their staff." Characteristic of the introduction of NPM in 
the asylum office was the rebranding of the completion of certain jobs/tasks at the "street level" (Lipsky 2010) as "products". Consonant with management by objective approaches, these products have since then been counted as "output". ${ }^{13}$ The management focuses at increasing the output:

A senior official of the asylum office addresses a meeting of asylum caseworkers and seniors in the last week of January 2014. The atmosphere among the more than a hundred people gathered in a large meeting room of the office's headquarter appears a little tense. The motto for the year is projected on a slide in bold letters: Nous produisons / Wir produzieren (we produce). After announcing this motto amid murmurs in the assembly, the head of the directorate appeases his subordinates: "Of course, this does not mean that the production stands above everything." The ambitious yet realistic production target for the year, he states, is to reduce the applications pending from 18,000 to $5000 .^{14} \mathrm{He}$ continues: "By the way, in January ... we have already almost accomplished this target with about 2300 completions." But this seems only a cold comfort to the increasingly troubled personnel. (Fieldnotes, participation in event, early 2014)

The counting of "products" accomplished in a certain time period thus serves to measure "productivity". As a head of section stated: "Productive in this context means to attain with as few resources as possible as much production as possible" (Interview with head of section, autumn 2013). In consequence, the situation in the Swiss asylum office resembles that of the British asylum system, where Gill $(2016,88)$ observed "constantly 'increasing targets' and managerial tendency to demand 'more for less" fuelling the turnover in staff. In French and German asylum administrations, the preoccupation with productivity also seems to proliferate as Probst $(2012,217)$ stated: "besides revising decisions produced by the caseworkers, the principal role of the superiors is to pay careful attention that the employees 'produce their

13 According to officials, output statistics already existed earlier. But with the introduction of NPM principles, the orientation of management towards output numbers has been accentuated.

14 At the time of this event, there was still a considerable backlog of files, after a peak of about 19,000 first-instance decisions pending by the end of 2012 (SEM 2015c). 
numbers.' ${ }^{15}$ Most caseworkers I met felt that output numbers had become increasingly and often excessively emphasised by the management (see also Miaz 2017, 344-48). One of the most prominent concerns amongst caseworkers was therefore what they usually called "productivity pressure" (see also Fresia, Bozzini, and Sala 2013, 54-55). But where do these numbers come from?

I was told about the existence of a "strategic agenda", a two-year old document which had been co-written by diverse members of the executive board of the (then) Federal Office for Migration and which provides guidance to the steering committee of the asylum directorate (PILAR). How numerical productivity goals for the whole asylum office were actually calculated remained unclear to me, as probably for most caseworkers as well. It only seemed apparent to the caseworkers who talked regularly about output numbers that the goals of the management were lofty and hardly achievable (if not considered completely unrealistic). But this might relate to conjunctures beyond my gaze. In a discussion with two senior officials, they told me:

This year [2013] the targets have been clearly missed, but now actions are called which produce tangible results after the resources [the personnel] has been increased. We already wrote in an internal document to the director that one should 'liberate oneself' from purely quantitative targets, the simple counting of completions. This has not been well received, it came back with three exclamation marks. (Fieldnotes, headquarters, winter 2013/14)

This vehement reaction of the director could be interpreted, I suggested, due to a feeling that he is being forced to sell 'his' office's accomplishments to his superior - the Federal Councillor - and to the parliament with numbers and

15 Own translation from French. 
statistics. One of the officials laughed and confirmed my conjecture that it is not possible to sell them the quality ${ }^{16}$ of a hearing instead. ${ }^{17}$

The management board defines certain "output targets" for the whole directorate, which are then broken down to the divisions, to the sections and ultimately to every single caseworker. In agreements on objectives, individual targets of caseworkers are defined, and these depend on their experience, their additional competences, and their working time regulation. One head of section disclosed the targets he had received (which consisted also of 'soft' goals though) at the weekly meeting of the unit: "My executive goal states 1600 completions in the next six months; this makes about 170 completions, thereof 35 hearings, per month" (Fieldnotes, headquarters, spring 2014). This can be read as a textbook implementation of management by objective theory: according to the new public management literature (e.g. Schedler and Proeller 2011), knowing to have a share supposedly increases the motivation of employees at all levels and makes them feel their co-responsibility for reaching the overall goals of an organisation. This "decentralisation of responsibilities" aims at fostering their allegiance (ibid., 250-261). In agreements on objectives, individual targets of caseworkers are defined, and these depend on their experience, their additional competences, and their workload. It is important to note that not every job completion at the street level counts equally. For instance, asylum decisions and deletions of asylum applications counted as 'products' at the time of fieldwork. Hearings, instructions of applicants, treatment of applications for re-examination, applications

16 One measure for the quality of decisions*, however, was sometimes employed: the cassation quota of first-instance decisions" for formal reasons at the Federal Administrative Court (FAC). The general cassation quota cannot be taken as a measure, as it is not only influenced by the quality of decisions" but also by evolving practices after revisions of the asylum act: new practices" lead to higher cassation quotas until they are "evened out" [eingependelt]. Consequently, only the cassation quota for formal errors (e.g. incomplete facts of the case or violation of the right to be heard) was an indicator for the legal quality of decisions" and could be actively reduced (Fieldnotes, headquarters, winter 2013/14).

17 The asylum directorate also had a quality manager, Stephan Parak (until mid-2018), who analysed the quality of asylum casework and made suggestions for improving the quality of administrative tools and processes, hearings, and decisions. He initiated many improvements in this regard, but the administrative resources available to improve quantity are still higher than those directed at the quality of casework. However, he did this work for about 500 officials in the asylum office alone. 
filed abroad, and other tasks did not count as 'products'. ${ }^{18}$ And beyond this, the expenditure of time for a completion can vary a lot; main hearings can take from an hour to a day (without preparation time), while decisions can be written in half an hour or take several hours or days, depending on the complexity of the case. In administrative statistics, cases with 'further investigations' are distinguished from those without; but even this distinction does not reflect the fact that efforts for investigations can vary tremendously. When I asked a caseworker about these productivity targets, she stated:

I mean I understand that the office makes productivity targets, but I don't find them well devised. Because simply to say, some three decisions per week, this does not well represent our work. There are decisions, which you have written in half an hour, I can produce a lot of those, but then you also have decisions, which take you more than a day, and with investigations even considerably more. Then you really have to argue and to deliberate, and I just find there you compare apples and oranges, and this is not that fair. (Interview with caseworker, autumn 2013)

The uneven accounting for different tasks can be interpreted as an incentive to do more of what counts and less of other tasks (see also Brodkin 2006). However, it would be wrong to conclude that the management always anticipates such incentives. On the one hand, many parts of work are related, since often tasks that do not count as 'products' have to be accomplished as preliminary work for the 'products' that count. On the other hand, the representation and comparison of various types of work in numbers has its practical limitations.

18 Lately, more of the things that caseworkers do count statistically. 
Figure 16: "Production" of section counting statistically relevant completions

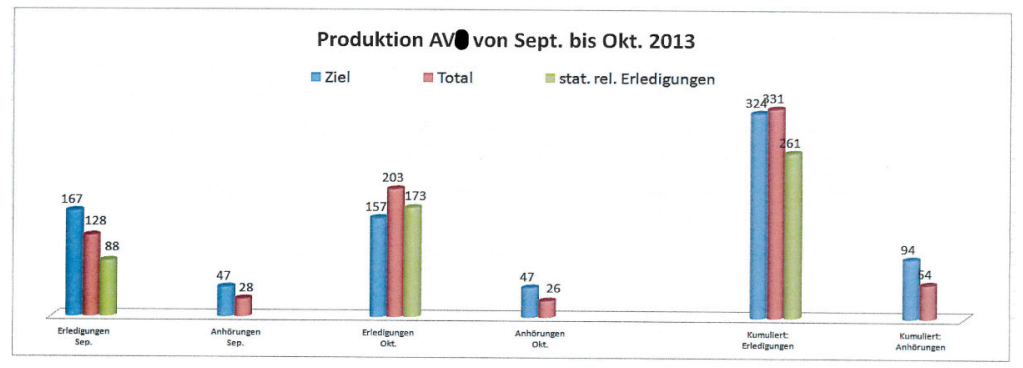

(Source: Fieldwork materials, winter 2013/14)

Indicators and forecasts compose metrological networks of governing asylum, universals which render work countable and the objects of work traceable (see Latour 2005, 227-29). Sections' good output numbers are celebrated in meetings, bad ones justified (see Figure 16). The results of quarterly counts were moreover compared to other sections, as this the statement of a head of section at a section meeting shows:

Concerning the production in our unit: it is comparable to that of other sections of the division two. The range lies between 380 and 400 statistically relevant national applications settled. Our section is in a good position with 391 completions. Nevertheless, the targets, which are ambitious (as is known), have not been met. (Fieldnotes, headquarters, winter 2013/14)

Caseworkers conduct their own calculations on how to achieve the numbers of their objective agreement. They were asked to make sure all their products were correctly attributed to their monthly production statistic. Therefore, many of them kept books of their (statistically relevant) work. I once heard a story about a more experienced caseworker taking advantage of an unknowing new employee, to whom he delegated non-counting tasks and took over the statistically counting ones (see section 8.3.1). While this is certainly a rather exceptional extreme case, it points to the dubious effects rewarding caseworkers for mere output can yield for those concerned (see Deming 1986, 
101-2). But to what extent does the emphasis on productivity affect the trajectories of cases and their outcomes? ${ }^{19}$

\subsubsection{Productivity Pressure: Reshuffling Encounters}

The NPM imperative to focus on 'output' statistics has led to a number of adaptations inside the public administration. During my fieldwork, I became familiar with a range of strategies related to NPM, which shape the spatiotemporal trajectories and associations (including outcomes) of cases-in-themaking and are reshaped in practices of assembling cases. They varied in their scope, from more explicit arrangements to increase output adopted across all sections for a certain period to more implicit (but not necessarily informal) arrangements to deal with the output requirements, which may also be limited to a few sections or a single section, and consist of ad hoc measures adopted by only a few caseworkers or a single caseworker to reach their targets. During fieldwork, I learnt that in some divisions and sections, the superiors generally put more pressure on their subordinates to reach output targets while in others they shielded them from pressure they themselves experienced 'from above'. In the following, I will outline first some of the strategies and arrangements to influence the time, duration, and order of encounters with cases and then tactics with a limited scope that reflect particular motives.

\section{Concerted strategies and arrangements to increase productivity}

Various rather stable and pervasive strategies existed to deal with increased productivity targets at the time of my fieldwork. Some of these strategies directly altered the trajectories of case files, while others influenced the terms of processual events. I will only exemplarily mention two strategies developed to reduce the complexity of a task.

A strategy temporarily in place for applications from certain countries of origin with a high rate of acceptance was to change the internal positive proposal, a writing device. The internal sheet for the case-specific substantiation of a positive decision* was replaced by a simplified form on which caseworkers could tick off the grounds from a list with given criteria (see section 6.5.1). This generic approach obscured the case-specific consider-

19 Parts of sections 8.2.3 and 8.2.4 have already been published (see Pörtner 2017). 
ations leading to the positive decision. ${ }^{20} \mathrm{~A}$ similar yet more contested and less stable strategy to increase productivity was limited to a very specific set of cases: Eritrean cases from 2010 to 2012. It allowed for the complete omission of the main hearing if on the basis of the first short hearing the grounds for asylum had been considered as established. This was documented with a few simple ticks and a signature on a form that stated the conditions for this type of decision* (internally therefore referred to as "tick-decisions"). This re-arrangement allowed for omitting core components of case-making - the encounter of the main hearing, and the protocol as its materialisation in the case file - and had thus profound implications. The often very short statement about the grounds for asylum generated in the first hearing had to suffice to judge the claimant's 'well-founded fear' of persecution. In these cases, their association with their country of origin mattered. Senior officials considered this a "petty evil" because, following a leading decision by the appeal body, basically all claimants from this country had to be granted either asylum or humanitarian protection (temporary protection). Yet, in the eyes of caseworkers I talked to, the superficial associations sufficient for granting asylum in this country category stood in marked contrast to the meticulous associations required in other case categories.

\section{Tactics to increase productivity with limited scope}

Besides such arrangements to increase productivity with a larger spatiotemporal scope, I also observed a range of local and ad hoc strategies of officials and sections to improve the numbers. Consistent with NPM doctrine, organizational subdivisions are not only assigned shares of cases and targets for their processing (see subchapter 6.3), but also put in competition with each other. Individual caseworkers are not just 'benchmarked' against their output targets, but also against the performance of their colleagues. While the aim here is not to point to the detrimental consequences of such competition, the - at times unforeseeable - turns and twists of cases trajectories throughout the organization could not be adequately grasped without taking its effects into consideration. Following the path of 'productivity' on this avenue brings to the fore a number of moves adopted more or less officially and which serve to improve or maintain the competitiveness of sections and individuals in the organisation. We learn that there are more and less valu-

20 This practice has been revised since my fieldwork. 
able stages of files, attractive inexpensive completions, and files that offer quick gratification.

An example of a valuable stage of case files is that of so-called "liquid files". Liquid files are those ready to be decided - i.e., those with the main hearing conducted and (and no 'further clarifications' to be conducted). But why are they more valuable than files of claimants ready to be heard? Arguably, the main reason for this is that decisions are a more secure metric for manoeuvre in the play of numbers than hearings: hearings are to be organized by a separate unit and usually require a lead time of three to four weeks (in the headquarters; shorter in the reception centres). There is also considerable uncertainty when estimating the duration of hearings - they will be planned for either half a day or a whole day, but things can always turn out differently, starting with one of the participants not showing up. As long as files are assigned to caseworkers of a section and physically on their shelves, they are safe. But as soon as they are sent to the archive, they can be potentially ordered by a reception centre with a (temporary) low workload. Obviously, such a 'hoarding' of files can in turn result in a poor utilisation of resources (see section 6.3.2), which the management board attempted to avoid by controlling (since 2012) "capacity utilisation" monthly. But cases in 'valuable stages' are only passed on if necessary, because this decreases the relative output share of the respective section or caseworker.

Moreover, officials also are in varied employment positions - some have worked for a long time in the administration and are sure of their posts; others only started to work in the administration recently or await promotion and feel (not without good reason) the renewal of their temporary contract or advancement to be dependent on their output performance. Amongst the heads of divisions and sections, this is reflected in variable degrees of submission to output targets. According to one caseworker, "We have a good and sensitive head of section, who is a bit submissive to authority and does not question such output targets, but feels under pressure and wants to reach the hundred completions, no matter what the cost are" (Interview with caseworker, autumn 2013). Others, however, question both the sense and necessity of ever-higher productivity targets and attempt to shield their subordinates from the pressure, for instance, by taking the responsibility for (potentially) not meeting targets. Yet others "do everything for their people", but have only their sections in mind, as another caseworker expressed about a head of section: "Then he does things, which are going too far, like drawing 
a list of all disappeared with open application and order them, although the files are not in his competence, and that way polishes his statistics" (Fieldnotes, conversation with caseworker, spring 2014). Another official acknowledged that "some people just care for their numbers" and they would not care about the consequences of their moves.

A last move adopted to improve the numbers (at least in the short term) that can be mentioned here, is to "excavate" files that offer "quick gratification'. This is how an official told the - recurring - story:

What do we do now? We just have to increase the output and we have hired so many new people, now it has to go up. (...). Then a head of section came with the astute idea: "now, let's just take all the Afghan and Tamil families of five and seven [cases which comprise of seven family members] out of the basement, because then every decision" yields [five or] seven completions ['tallies']". And then somehow another one came, who thought even a step ahead, and threw in: "yes, but what are we going to do then in the third quarter [of the year], if there's no families of seven anymore in the basement and the same output targets are expected of us?" Yet it was said: "until then we are confirmed in our posts". (Interview with caseworker, autumn 2013)

Hence, the strong focus on numbers and the 'inevitable' necessity to reach output goals can foster inventions with rather doubtful effects. But they can be explained by the partly precarious positions of employees or their endeavour for promotion. 
Figure 17: Newspaper article on productivity pressure: "In the Asylum Factory"

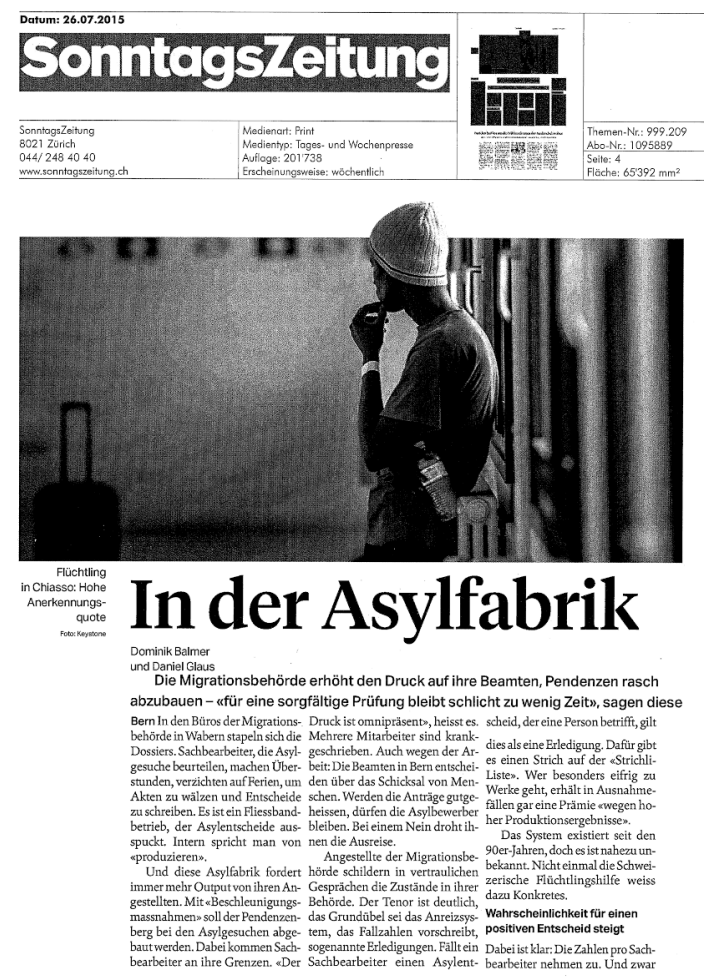

(Source: Fieldwork materials, 2015)

What these examples reveal is that the new strategies and tactics related to New Public Management principles govern the office and at the same time alter the spatiotemporal trajectories of cases in considerable yet at times unforeseeable ways (see also Painter 2006, 761). The examples also show that cases are now encountered as a means to increase productivity, and their trajectories are altered accordingly. This insight resonates with Gill's (2009) notion of "presentational state power", which refers to the influence on decision-making of the institutionalised timing and spacing of encounters between asylum sector workers and asylum seekers. In a more recent piece, Gill (2016, 51-52) has pointed out various institutional rationales at work in the governing of asylum in the UK that entail a dilution of ethical encounters with asylum seekers in the administration. Abstract objectives such as out- 
put numbers mediate case-making in crucial ways by changing the governmental arrangements officials are working in. It does not mean that caseworkers do not care about asylum seekers in encounters with them. Rather, as Gill $(2016,136)$ pointed out, "moral indifference in bureaucracies often arises as a result of an emotionally conflicted state wherein empathetic compassion is overridden by a variety of other concerns" (see also Fuglerud 2004, 29). Additionally, the NPM discourse of productivity ties the officials to the common goal of increasing the quantity (particularly) of rulings, which tends to stand above all other concerns and to become an unquestioned mantra. A media overflow about such practices occurred in 2015, when a feature article in a major Swiss-German newspaper cited "internal sources" of the SEM to highlight some of the problematic facets of the management's emphasis on productivity (see Figure 17). ${ }^{21}$ Overall, changes in the material-discursive assemblage such as those related to the introduction of NPM can significantly change the arrangement in which asylum seekers and their cases are encountered.

\subsubsection{Politics of Deterrence: Speeding up and Shelving Cases}

The trajectories of cases-in-the-making, however, are influenced by another powerful rationality: that of minimising the 'input' in the office's equation - new applications. Of course, there is more to this: Avoiding asylum applications is related to the governing of migration according to economic principles by attracting 'wanted' migration and deterring 'unwanted' migration (see section 4.1.1). As by and large falling into the category of 'irregular' and thus 'unwanted' migration, asylum seekers become subject to a politics of deterrence that also leaves its imprints in case-making (see also Hardy 2003). The number of asylum applications in Switzerland depends on various factors, many of which are beyond the scope of its institutions' influence. Yet, there seems to be a political consensus in the parliament and public administration that the setup of the asylum procedure is key. Particularly the timing of treatment and the outcome of applications are considered key factors

21 The feature article appeared in one of the three major Swiss-German Sunday newspapers, the Sonntagszeitung. The lead reads "The migration authorities increase the pressure on their officials to reduce the numbers of cases pending - 'for a careful examination simply not enough time remains' the latter say" (Balmer and Claus 2015). 
having a substantial influence on the relative 'attractiveness' of Switzerland as a destination for asylum seekers. The core rationale I heard reiterated in many versions during my fieldwork goes like this: "if we are too generous in the granting of asylum (and humanitarian protection) compared to other countries, we generate a pull effect, i.e., we will attract many asylum seekers of this sort. Therefore, we have to mould the procedure in a way that deters potential asylum seekers and minimise the entitlements" (Fieldnotes; see also Holzer and Schneider 2002). This rationality seems widespread in Europe as Fuglerud (2004) highlighted in the case of Norway:

Care is always taken that these principles [guiding the handling of asylum applications] should not be more 'liberal' than those found in nearby countries. The assumption is that if such care is not taken, the news will spread and applicants may choose to go to Norway instead of some other country. (Fuglerud 2004, 33)

This discursive framing resonates with the highly politicised public debate on immigration and so-called 'bogus' asylum seekers in Switzerland and elsewhere (Zimmermann 2011). Such a politics of deterrence is not an official policy but a powerful discourse permeating and thus mediating enactments of the asylum dispositif. Accordingly, a lot of legislative and organisational activism has been devoted to what the head of the asylum directorate termed gatekeeping: measures to limit the number of people filing an application in Switzerland ${ }^{22}$ (see also Nevins 2002). According to Holzer and Schneider $(2002,38)$, countries generally have two possibilities to reduce their attractiveness as destinations for asylum seekers. They can either attempt to reduce the incentives for asylum seekers to file an application on their territories or adopt measures to restrict who is eligible for asylum. Legal and organisational arrangements play a crucial role concerning for such gatekeeping. They reshuffle the timing and spacing of cases' trajectories with the aim to limit the overall number of applications. On the one hand, they consist of measures to influence the order, timing, duration of the procedure for a

22 While the official rhetoric implies that gatekeeping is solely about "minimising the number of manifestly unfounded asylum requests" (communication from senior official), the internal rhetoric I witnessed in the office suggests that gatekeeping is also about limiting the number of potentially well-founded asylum requests. 
certain category of applications. On the other hand, they stipulate a range of locations for their assembling.

\section{Prioritising 'likely unfounded applications'}

According to a member of the management board, a simple strategy lies behind a series of organisational arrangements for gatekeeping: the rapid processing of "likely unfounded" applications that is contrasted by a "first in-first out"23 order for all other applications. Thereby, the order and duration for the processing of applications is changed by speeding up some cases - and so slowing down all the others, who have to wait longer in the archive to be processed. When examined more closely, arrangements and moves for gatekeeping appear more differentiated and complex. Very early in the process, cases are classified according to three priority levels (1-3), which reflect various considerations: types of decisions* (positive, negative, non-admission), various ease of deportation to countries of origin (enforcement categories 1-3), and workloads estimated with or without further clarifications. Moreover, high priority is attributed to claims from certain countries in order to 'decrease the attractiveness for probably unfounded applications' and in cases of delinquency or cantonal requests. Positive decisions* are considered to have a 'pull effect', which is why they have been only of second or third priority. ${ }^{24}$

Admission rates may vary significantly over time. However, they are not considered very representative, because of their aggregation to the year of completion of an application, whose timing and spacing varies for all the reasons mentioned above. But what can be said is that older cases usually have a higher rate of admission. As one official said: "with time comes admission, that's just how it often is" (Fieldnotes, conversation with caseworker, spring 2014). This is a logical consequence of the suspension of cases with a probably

23 This simply means they are processed in the order of entry.

24 Priority levels and categories change over time: the three levels mentioned have been reduced to two that are now publicly outlined at the website of the migration office (SEM 2016b): "likely unfounded applications" have the highest priority and are rapidly processed; for all other cases which tend to involve some form of protection, the oldest cases are processed first. While these general principles are publicly declared - which can be itself read as performative enactment of the politics of deterrence-more detailed and confidential principles regarding the priorities of cases (namely regarding the enforceability of expulsions) still exist. 
positive outcome in the prioritisation, but another reason for this emanates from the ethical considerations of caseworkers. Most of them would agree that it takes more to reject the claims of asylum seekers who have had to wait for 'too long' for their decision* due to a low priority, delays in the organisation, or case backlogs (see Gibney and Hansen 2003).

But what does the reshuffling of cases for gatekeeping mean for case-making? How are case files' trajectories influenced by this prioritisation? The attribution of files to the caseworkers is a task of the heads of sections. But it is not until they are deemed "ripe" (Latour 2010) for further processing that they are effectively attributed. The heads of section and the caseworker consider the right timing for the next processual event when receiving a case file according to its category in the priority levels. Depending on their assessment, the case file is put on a caseworker's desk with a note "urgent" or "to be treated", placed with another pile of case files on the shelf, or put on the cart to be sent to the archive. In ZEMIS, the case then has to be reassigned to the newly responsible caseworker.

\section{Inventing new procedural arrangements}

As a response to a rise in 'likely unfounded' applications from certain countries, whose claimants were suspected to profit from longer waiting times, the management invented both the so-called "48-hour procedure" and the "fast track" that became arrangements to deter asylum seekers. A prime example for the necessity to introduce the former was the 'phenomenon' of "Roma [from Hungary and Bulgaria] who come to Switzerland in autumn and file an application to overwinter in the reception centres, because they know they will not get their negative decision* until spring" (Fieldnotes, reception centre, spring 2013). After proving a 'great success' in this case, namely a significant drop in applications of this type, the arrangement was taken as a blueprint by the management and its scope extended to further categories of countries of origin. Cases falling into these categories had highest priority and their claimants were not transferred to the cantons; their decisions were (almost) exclusively taken in the reception centres. Although those processing case files on this track in the reception centre I talked to acknowledged that its branding as a 48-hour procedure did not mean that decisions were really taken within such a short time span, it is still faster than earlier and fulfils the performative goal of deterrence. At the other end of the spectrum, claimants whose cases are of low priority and processed according to the 
"first in-first out" principle may have to wait for their decisions for quite a while. This can be related to the asymmetrical relation of speeding up and slowing down of cases. What Adey (2006, 89-90) highlighted in example of airport passengers - that their mobilities and moorings are intimately related - is thus also true for asylum cases.

\section{Suspending tenuous case categories}

In times of political turmoil in countries of origin, the management board may draw on a technology to suspend the treatment of cases until further notice - the so-called 'suspension management' with three stages of suspending case-making. This is supposed to give them time to look at how other European countries deal with the new situation and regulate the admission of new, tenuous categories of asylum seekers. Again, a major motive for this guarded course of action seems to be the fear of becoming too attractive as a destination country by being overly generous compared to other countries. Before the suspension of case-processing for a country of origin is lifted again, a field mission will visit the region and assess the security situation. After a meeting involving representatives of other ministries and the UNHCR, the suspension may be lifted. Officially declaring conflict as civil war in a country of origin means that applicants who do not acquire asylum status will still receive temporary protection. A head of section involved in the lifting of suspension of case treatment for a country in turmoil expressed her opinion at a small practice reform meeting of a working group counselling the management board:

I will have to make clear to the management board that it will not have a 'pull effect'; that we lie rather in the European average with it. And I will argue that it is better to adapt the internal practice in this direction than to wait for a public and visible cassation by the Federal Administrative Court. (Fieldnotes, practice reform meeting, headquarters, spring 2014)

This quote points to a facet of the politics of governing asylum: making things public is often considered to have unwanted effects such as negative media coverage or 'pull effects' (see also Mountz 2010). The change of practice may also take the opposite direction; if the situation is expected to significantly improve in a country of origin, cases may be shelved until the enforcement of expulsions is considered reasonable again (which is usually to be sanctioned 
by the appeal body). In both cases, suspension adds waiting time for applicants and potentially alters the terms of encounters with applicants and their case files in the administration as other legal and managerial arrangements of the asylum dispositif evolve. Their files may collect dust in the archive for years until they become due in sequence or even urgent as "old cases" [Altfälle].

[The asylum office] just let[s] [claimants] wait for a very long time and then suddenly [their cases] are processed. Sometimes I find it steep: then you get one of these cases, for instance of [a claimant] from Sri Lanka, who really has no grounds [for asylum]. I just had this recently ... after three and a half years, one fine day, you get this letter, ok, within 56 days you must leave [Switzerland]. And I don't consider this acceptable anymore. (Interview with caseworker, autumn 2013)

Caseworkers seemed to be often quite critical about the effects of such a "suspension management". While the suspension management is generally a reaction to changes in countries of origin, the form it takes in practice appears also related to the managements' fear of generating a 'pull effect' for applicants from such countries (which is particularly marked in 'turbulent times').

Overall, the politics of deterrence produce geographies of asylum in Europe that turn 'location marketing' upside down. Switzerland is considered to be in competition with other European countries to become the least attractive (or at least a relatively unattractive) destination for asylum seekers. Despite paying lip service to a harmonisation of the European asylum system, countries still pursue what Wood (1989, 191-93) termed "beggar thy neighbour" asylum policies to decrease their relative share of asylum applications. This includes more restrictive asylum legislations and higher hurdles to labour and social welfare (Holzer and Schneider 2002). Yet, it also involves, as I have shown, sophisticated spatiotemporal arrangements of case-making in the asylum administrations that work by prioritising cases according to their anticipated outcome. Analogous to the different time regimes that rejected refugees experience (Griffiths 2014), asylum cases-inthe-making can go through pathways of "frenzied time" and "sticky" or even "suspended time" (ibid., 1994) - they can be accelerated and hastily settled or sent to the archive for long periods of time. This example reveals how the 
political discourse of deterrence, which is central in many parliamentarian debates and informs the circuit of legal reformism of the Asylum Act, fosters the development of arrangements in the public administration to impact encounters with case files in highly divergent ways. This can have tangible consequences for the outcomes of individual cases as well. As the moment of decision" rather than of claim-making is decisive for the evaluation of a wellfounded fear of persecution, claimants' eligibility may expire in the course of institutional suspension. Moreover, the suspension of likely positive decisions runs counter to claimants' potential integration as it keeps them in the limbo of asylum seeker status - a material-discursive borderscape (Rajaram and Grundy-Warr 2007) - that impedes socio-economic participation.

Together, these three rationalities - of law, productivity and deterrence crucially shape practices of case-making. They are leading to what I call the "case multiple" (similarly to Mol's, 2002 "body multiple") - a case having different 'realities' depending on the governmental rationalities according to which it is encountered and assembled: namely, as cases to be resolved in legal decisions"; as backlogs to be reduced and means to reach productivity goals; and as mediators of the amounts of future applications. The rationalities are moreover interrelated in significant ways. For instance, the legal is seen to be made more rigid by the legislator for reasons of deterrence. Legal articles are seen to be simplified or abandoned altogether for reasons of efficiency - or because they were too leniently applied and thus not conducive of a politics of deterrence. ${ }^{25}$ The interpretation of law may be delegated to the judiciary for reasons of efficiency. The rationality of efficiency may lead to the establishment of (too) pragmatic approaches to case-making and resolutions that run counter rationalities of law (e.g. hurrying through cases, reshuffling them; acting without a legal basis) or of deterrence (e.g. quick positive decisions). In turn, rationalities of deterrence can contradict efficiency (e.g. excessive search for means to reject; inefficient reshuffling of cases) or law (bending or suspending the legal, e.g. with a 'waiting period' until cases' official registration). Thus, the material-discursive arrangements of the asylum disposi-

25 A senior official suggested this to be the case with Article 52.2 of the Asylum Act that had allowed for a reunification of people with refugee status in Switzerland beyond the core family (as defined in Article 51.1) under certain conditions. 
tif become even more intricate, if these different and at times contradictory rationalities of government are considered.

\subsection{Asylums of Reason?}

This subchapter attempts to grasp some of the conjunctures in which the asylum dispositif needs to be thought - its relations to the 'outside world' - and indicate some of their effects. As indicated at the very outset of this book, the dispositif has emerged in a particular historical conjuncture of the formalisation and constant revision of asylum law, the rise of populist parties and the politicisation of asylum seeking in and beyond Switzerland (see subchapter 4.1). Consequently, case-making is affected not only by "epistemic anxieties" (Stoler 2009) of unknowability and related modes of truth-telling (as discussed in Chapter 7), but also personal anxieties related to the "political' consequences of practices. The atmosphere surrounding case-making may thus - again depending on one's location - be variously influenced by anxiety (section 8.3.1). Both the unpredictability of application numbers and kinds and constantly changing legislation and case law require constant improvisation of caseworkers in their everyday practices (Jeffrey 2013). However, I suggest that the need to resolve driving practices of case-making also sparks more anticipatory, experimental modes of government and of the dispositif's enactment. Different forms of experiments with various scopes speak for a sort of 'experimentality' of the dispositif(section 8.3.2). Ultimately, I point to the fact that asylum dispositif exteriorises a host of associations in case-making: it operates as if there was no history and geography of producing difference (namely of colonialism, of uneven resource extraction, of the destruction of livelihoods and of imperialist wars.). This, I suggest, is not only necessary for its enactment but also productive of certain relations of difference. I provide a reading of the dispositif that considers itself as a feature of reconstituting a certain coloniality of power. I moreover suggest that it is not only nurtured by its own overflowings (see subchapter 7.3), but partly also by removing associations of capitalist modes of production from scope (section 8.3.3). 


\subsubsection{Atmos-Fears}

It's really a political Sword of Damocles you have over your head. (Interview with caseworker, autumn 2013)

I was surprised to find that anxiety is a crucial facet of both stabilising arrangements of the dispositif or transforming them. Yet, the anxiety I encountered was usually not about potentially fatal consequences a wrong decision* could have on applicants and their lives. The anxieties of people in the office rather seemed to concern the media, the nation, and politics - in ways I will briefly outline here. Such anxieties not only haunt officials in the Swiss asylum office. Gill $(2016,16)$, for instance, stated in the case of UK asylum officials that anxiety "nagged almost every functionary I came across". While it may be less surprising that those who are waiting for asylum decision* are prone to anxious atmospheres (see Darling 2014) or have a "wellfounded fear of justice" (Douzinas and Warrington 2012), it seems crucial to acknowledge that also (some of) those involved in producing these decisions* may experience states of anxiety.

One caseworker had the following explanation for such an atmosphere of anxiety in the office:

And it is especially about the atmosphere of the nation: the minaret initiative, ${ }^{26}$ the deportation initiative ${ }^{27}$ and so on. There you always realize, all the people of the senior management, particularly our Federal Councillor [Sommaruga] who is from the Social Democrats have to pay extreme attention that the right does not accuse them of being too lax - and there is just an extreme pressure. And then it's also about money, right? It costs a lot of money once the people are here, it is like that, and one has to admit this in fairness, usually live from social welfare for years. Well, that is expensive, right? (Interview with caseworker, autumn 2013)

26 The caseworker referred to the popular initiative "Against the construction of minarets" for which 57.5 per cent of the Swiss voted in favour on 29 November 2009 (Schweizerische Bundeskanzlei 2009).

27 Another popular initiative, "For the deportation of criminal foreigners (Deportation initiative)", was supported by 52.3 per cent of the Swiss voters on 28 November 2010 (Schweizerische Bundeskanzlei 2010). 
It appears that those in charge of the management are seen to anticipate how the practice* of the office is read from the outside - and because a Councillor from the left is head of the Federal Department of Police and Justice they particularly fear accusations from the right of 'being too lax'. In a coffee break I spoke with two long-term caseworkers who work for more than twenty years in the office, since Federal Councillor Koller [who was head of the Federal Department of Police and Justice from 1989 - 1999]. One of them told me:

Since Koller['s time in office], you have to be afraid with all Councillors to do something wrong. All of them produce pressure and the strain in the office is therefore much higher. This is certainly true for Blocher and Widmer-Schlumpf, but also for the current Councillor [Sommaruga], even though she is personally much more likeable. She applies a lot of pressure via her director [of the office, Gattiker]. Probably she herself stands under an enormous pressure. (Fieldnotes, headquarters, spring 2014)

The caseworker explained thus the pressure and the tenseness in the office that find expression particularly in the productivity pressure but also to some extent in the politics of deterrence - with the atmosphere under a certain Federal Councillor. Together the two quotes provide an emic explanation for what caseworkers often perceive as an excessive emphasis of productivity by the management and the fear of a 'pull effect'. The example of the Dublin practice* concerning Greece was for several caseworkers an 'exemplary case' for the anxieties of the management (and beyond). One of them told me:

It just appeared exemplary to me with the Dublin practice*: there I would say (...) about from 2009 one realised that the Dublin enforcement to Creece was actually not reasonable anymore. But one continued to do it because the FOM was afraid to stand there with an egg on its face in front of the SVP [Swiss People's Party] and the political pressure and the public opinion if one suddenly says: essentially, we have the Dublin system, but nevertheless we do not enforce [removals] anymore to a Dublin state which was technically competent. Well, and there were numerous people who would have been forced to go back to Greece, who had to appeal against the [Dublin] decisions* within these five days - the appeal period is very short - and who did so. Afterwards the FAC, the Federal Administrative Court was afraid -in light 
of this political pressure - just to say: that's not possible anymore, there are untenable conditions in Greece, human rights are violated there, no more removals will be enforced. And then, what did the FAC do? On the one hand it feared to decide cases against this political pressure, on the other hand it was also afraid to send people into their death [calamity]. Therefore, one said: fine, let's make a Greece archive and every Afghan who makes an appeal against a Dublin decision* ends in this archive for the time being. But those who did not appeal, they just flew, they were flown to Athens and maybe tried again... And the others [who had appealed], they stayed and one waited for one and a half years and said: against this political pressure we just need a backing that we can eventually write a leading decision. And they waited until the European Court of Human Rights finally made a ruling in the case of an Afghan, contra Belgium I think. Then ultimately, after this ruling the FAC could say 'well if Europe says this, we simply have to' and the FOM said 'well if the FAC says, we simply have to' [laughs]. But before nobody had dared to just stand up and say: this is not tenable anymore in our view. (Interview with caseworker, autumn 2013)

The fear of the precedence appeared to be particularly widespread amongst the management who had in case of a major change of asylum practice* to be appeased that there will be no pull effect. ${ }^{28}$ Caseworkers could dissolve some of the pressure and anxieties about the momentous resolutions regarding others' lives by pointing to the practice* that prescribes them 'a lot' or their superiors (see Parak 2009). A further strategy of both caseworkers and superiors consisted in delegating responsibility to the appeal instance.

And, relatedly, caseworkers and superiors alike seemed to fear about their future in the office. All the newly hired caseworkers only received temporary contracts that had to be annually confirmed by the senior management. They therefore particularly struggled to meet the increasing productivity targets. Also, those who sought promotion were eagerly pushing themselves (and if already leading a team: their subordinates) to excel concerning output numbers. This partially explains, for instance, attempts to

28 For instance, in the case of a Syria practice * change, I attended a meeting of the team having the practice* lead: a key issue of this meeting was how they could ensure the management that the change would not result in what the management saw in their eyes as the "Eritrea horror case" (Fieldnotes). 
reshuffle cases (according to their 'yield') in order to achieve benchmarks or excel in the competition for high output (as indicated in section 8.2.2). Here's an example of Catherine, a caseworker, who told me about how she was suffering under the productivity pressure. She told me, seeming very upset, that she has severe backaches, but still has to work because she still has to accomplish so many hearings and decisions:

This month, they did not account for half of my hearings and decisions. Like this I of course never reach my productivity targets. ... Now I have to prove that I did them which is simple for the hearings because of the invitation and DOPO [hearing management database], but not for the decisions. I just pass them to Thomas [the head of section] for the signature, then I have no further trace of them. I don't know either how these statistics are produced. But I never experienced something like that, this is only possible in the FOM. But I was naive at the beginning too. Once you know how it works you can also play the game. In the old section, I made the hearings for an office colleague for some month and thought: well, it doesn't matter who writes the decision* and accounts for them, this surely counts for the unit. But then I was told at some point that my productivity was insufficient. In the end it's only the tally marks that count. (Fieldnotes, headquarters, winter 2013/14)

Catherine was obviously not happy at all with the work in the office and soon after that conversation quit. It is thus not only an anxiety related to the political effects at work, but also an economic one: even if the portrayal of the caseworkers that "only tally marks count" may be somewhat exaggerated, output numbers loomed large in the office. They were a reason why (particularly) conscientious caseworkers I met felt impelled to work long hours.

A further anxiety I encountered in the office related to the political and/ or economic pressures was the fear to lose one's face. One caseworker told me about his superior whose fear of losing his face manifested in the way he assessed the decisions* of his subordinates:

And we have a head of section who has himself never written an asylum decision*, not a single one. He has travelled around the world and is a nice person ... But he just has zero confidence, has a huge fear in front of the other head of asylum sections of the office that he could make a mistake. Therefore, he wants that we make preferably no positive decisions* at all. - Ah, 
really? Are those the decisions* that are questioned? - Yes, because always if we want to make a positive decision*, we hear 'uh, are you sure? Don't you have to make further clarifications?' I mean we make innumerable negative decisions* without further clarifications (...). In our section, there is a quite strong pressure to make no positive decisions* if possible. (...). And I think this is also the case in a part of the other sections: depending on what kind of head of section you have. (Interview with caseworker, autumn 2013)

This example in my eyes indicates that anxieties of key personalities such as heads of sections can have consequences quite detrimental to the way cases are resolved in their sections. And it moreover hints at one potential root of such anxieties: the lack of experience that makes it hard to build upon sound heuristics and thereby appreciate and defend a certain scope for interpreting the practice* (as well as output targets).

It seems that different anxieties affect case-making. Some officials fear for their job or promotion for getting the numbers wrong, others are afraid to produce a 'pull effect' precedence and the disgrace inside the office or publicly associated with it. Of course, such anxieties do not affect everyone in the office. Many of the well-established senior officials and caseworkers I met seemed hardly affected by them or at least did not become swayed by them. Yet, for all of those captured by such anxieties, the considerations of case-making seem to have subtly but significantly shifted. Cases may become resolved considering not only their legal stakes but also these anxieties of (political or personal) overflows.

\subsubsection{Experimentality}

A facet of case-making is the surprising flexibility of the office in finding resolutions to problems arising from the exigencies of the various rationalities introduced above. One could say that the governmentality that pervades the dispositif, the need to resolve not only generates its own problems that again require resolutions (see subchapter 8.2 ), but seems to be paired with what I call an experimentality ${ }^{29}$ - a regime of governing that is characterised by a

29 The notion of 'experimentality' as a regime of governing was originally coined in health-related research: in the context of clinical trials in low-income countries (Petryna 2007) and, for instance, applied to the case of HIV treatment programmes in Africa 
proliferation of experiments: not experiments 'with' asylum seekers, but the legal and administrative arrangements of processing their cases. Practices of experimentation, of trying new things, adapting, anticipating and mobilising new tools, can be found from the caseworkers to the management. Experimentality refers to a regime of governing that is about testing and shifting the scope of the legal and the possible. It is less a government-by-exception than trial-and-error mode of government, in which experimental stages are normalized or overturned. The experimentality of the dispositif can be understood as an important force for its constant transformation. I will provide a few examples of the practice of experimentation with different scope and visibility.

An example of everyday experimentation in the asylum sections is the practice of producing "test" or "decision balloons" ${ }^{\text {"30 }}$ for writing decisions that test a new country practice* of the office or the scope of (new or ambiguous) legal provisions at the court of appeal. If such decisions are not challenged by the court, they extend the scope of terms or technologies (e.g. LINGUA tests, COI, fingerprints) and provide a legal basis for a new practice* - or they open new avenues for argumentation of what counts as a legitimate decision* under these conditions. And if they are challenged, they offer new case law that details the scope of terms or technologies. Such experimentation with the scope of law supports the emergence of new or better heuristics around cases of doubt (see section 4.2.3).

\section{Back- and front-stage experimentation}

Whereas test balloons are about actively testing the scope of law, other experiments test the scope of the possible. While in the first form of experiments the legal is sought for maintaining a new practice, in the second the legal becomes suspended in order to pursue new pathways to resolve cases or problems. The second form can be considered back stage experimentation as it often involves testing the dissociation of practice from legality (see also Heyman and Smart 1999).

(Nguyen 2009). But in these examples, the notion of the experiment relates to practices of the medical sciences, not public administrations.

30 Such "test balloons" are not only reserved to members of the asylum office, but seem to be also a 'technique' used by legal representatives of applicants in cases of appeal. 
Ways of enacting the politics of deterrence introduced above involve such experimentation: in the competition between countries of the Dublin agreement, authorities experiment with the spacing and timing of leaving 'traces' of competence in the international database to 'produce' the least competences possible for applications of asylum seekers (see Pörtner 2017):

\begin{abstract}
A senior official told me that France had for a long time a forerun phase [in its asylum procedure], a sort of 'reflection period', until the actual procedure started and the fingerprints were taken to avoid producing 'unnecessary' competences. For a few weeks, he said, Switzerland tried to do the same: they did not take the fingerprints on the first day yet. If somebody disappeared forthwith, one did not 'create competences' this way. But, he added, this practice had to be ceased already after few weeks because it violated law and was thus illegal. [For example] with the Roma we once had here they told us that they had been in France before. They got the run-around for weeks. Time and again the authorities got rid of them if they wanted to file an asylum application on the grounds that they did not have interpreters at their disposal. - "Attrition tactics?" I ask. - "Yes, exactly." - "Probably all states in the current system develop their tactics not to be competent, right?" - He does not contradict. (Fieldnotes, spring 2013)
\end{abstract}

In my experience, such practices may, however, be internally contested and spark protest and even resistance from those having to enact them. Or they may be stopped by the management. And applicants have found their own 'tactics' to contest becoming simply captured in terms of Dublin against their will - for instance by using these suspensions of registration for simple overnight stays in reception centres on their further journey to another asylum destination.

The re-cording of claimants' lives in terms of Dublin is thus not self-evident but contested by tactics of both states and those seeking refuge. State agents' 'experimentality' regarding the timing of fingerprinting asylum applicants resonates with the insight that in governmentalised states the use of law appears largely tactical but is exactly sustained in sovereign moments that are shifting the scope of legality (Erlenbusch, 2013). But backstage experimentation not only involves suppressing or dilating legality in ways detrimental to applicants; it may also happen in ways that are to their advantage. For instance, in an experimental move to simplify positive decisions in 
Syrian cases (and, of course, boost productivity numbers), a simple form with a few tick boxes replaced main hearings and written internal proposals in the headquarters for a while. Many caseworkers and superiors who considered the selective lenience with Syrians a gross violation of equality before the law, however, opposed this practice. But there is also 'front stage' experimentation at work: the so-called Testbetrieb (pilot operations) was invented in the office to test the procedural effects of the latest restructuring intentions. ${ }^{31}$ It was approved by the parliament and made operational in Zurich as a laboratory of the future asylum procedure. It has been considered a successful experiment showing that changes in the parameters of the procedure affect the outcomes in the intended ways (see SEM 2016a).

Experimentality is, I suggest, a key feature of the formation of governmental arrangements, at least in the case of highly volatile and uncertain issues such as asylum. From the perspective of street-level officials, reforms of law and practice* resolve some problems but at the same time generate new ones (see also Li 2007). However, problematisations of law and practice* (by postulating and foregrounding problems or unintended effects) nevertheless ask for resolutions within the frames of government - usually quick fixes - and hence foster experimentality.

The legislative attempt for gatekeeping found, for instance, expression in the addition to the central Article 3 of the Asylum Act, the refugee definition, in a recent revision. The new paragraph states that desertion is not recognized as a reason for being granted asylum. ${ }^{32}$ It has explicitly been directed towards Eritrean asylum seekers, who are persecuted after desertion from the national service and represent a large share of asylum applications in Switzerland (Haefliger 2013). Everyone in the office I talked to about it found it completely pointless, because it only makes common practice* explicit: desertion alone had never been the reason for granting Eritreans asylum (or equally Syrians, see BVGE 2015/3). The grave and disproportionate consequences of desertion amounted to persecution, according to case law

31 The most important argument for the restructuration of the asylum procedure is "acceleration" (SEM 2018a).

32 Article 3.3 of the asylum act now states: "Persons who are subject to serious disadvantages or have a well-founded fear of being exposed to such disadvantages because they have refused to perform military service or have deserted are not refugees. The provisions of the Convention of 28 July 1951 relating to the Status of Refugees are reserved." 
(EMARK 2006/3). However, one head of section stated after the parliament had decided to adopt this clause in the Asylum Act: "When they [the parliament] change the law that way, they implicitly expect that we won't recognize Eritreans as refugees anymore. I don't know how the Federal Office for Migration will get out of that tight spot!" (Fieldnotes, headquarters, autumn 2013). Thus, this senior official saw in the change a message to the office beyond the mere legal text: to change its Eritrea practice. Accordingly, the office had to find a way to resolve this tension between what they considered to be the expectations of the legislator and the need to protect Eritreans fleeing severe punishment for deserting from the national service. ${ }^{33}$

In times of new public management getting the numbers right is often enough - as indicated above. This has also involved testing the limits of what is possible or bearable for the staff in terms of output targets, as this statement of a caseworker indicates:

But now, they [the management] are blowing it with the pressure to increase productivity out of all proportions. They ask for absurd performance improvement, from 60 to 100 completions per asylum division [four sections] in a month, and this is just the beginning - in the long term, the director wants 160 completions per division. (Fieldnotes, Asylum caseworker, Nov. 2013)

In turn, people in the asylum divisions of the bureaucracy always have felt forced to become inventive in finding new ways to increase numbers of completions.

Overall, I argue that experimentality and its techno-normative and often ad hoc resolutions must be understood in the context of a particular governmentality permeating the dispositif and producing particular practices. This trial-and-error mode of government I call 'experimentality' contributes to the flexibility of adapting arrangements of the dispositif in light of internal or external exigencies. In turn, it may render pathways for cases' resolution short-lived and constitutionally questionable at times. Notably, such experi-

33 As it happens, the Eritrea practice* has taken a marked turn in recent years despite little evidence for changes in the country. Temporary admissions are to be re-examined, and the enforcement of removal orders to Eritrea seems not sacrosanct anymore, either (see for example Jikhareva 2018). 
ments are occasionally actively resisted or evaded in certain 'communities of interpretation' across the office. This means in effect that reasons for doing things in certain ways are not only fragmented between schools of practice but also between domains unevenly affected by experimental modes of government. Furthermore, it often means that material-discursive arrangements related to case-making are rather discontinuous over time.

\subsubsection{Geographical and Historical Exteriorities}

The fundamental point of anchorage of the relationships, even if they are embodied and crystallized in an institution, is to be found outside the institution. (Foucault 1982, 791-92)

The need to resolve tends to exteriorise from the scope of case-making much of the differences and (dis)associations that are produced as an effect. I will only hint at some of these exteriorities (outsides) - and alterities (Others) - of governing asylum here: reflections upon two crucial undersides of asylum, namely relations of economy and coloniality. These reflections highlight the implication of the asylum dispositif in the (re)production of essential "moral geographies" (Smith 2000).

A first fundamental underside of governing asylum is that economic relations are omitted as exterior to the question of asylum eligibility, as a caseworker pointed out:

But what I recently thought about is that Article 3 [the refugee definition] is just a bit erroneously constructed: because I am absolutely convinced, you can come from any African country and be as gay as you want: if you are a millionaire you have no problem, zero problems. (Interview with caseworker, autumn 2013)

As this caseworker contends that intersectional overlaps arguably have an impact on persecution, yet applicants' relations to pecuniary matters are of little interest in the procedure and are moreover easy to conceal by the applicants themselves. However, there is more to this:

After the hearing, Chris, an experienced caseworker, noted that only in very few instances, refugees have to come to Europe because they would not be 
safe in the neighbouring countries either. Kwame, an interpreter of West-African descent, agreed and mentioned the example of Togolese refugees having sought and found protection in Chana. Chris concluded that if refugees travelled so far and came to Europe, there was always an economic component to it. (Fieldnotes, reception centre, spring 2013)

This second meta-pragmatic statement implies that applicants who travel farther for protection than explainable with from what they are fleeing and thus have additional, economic motives: they 'cross space' to reposition them in the history of capitalist relations - what a reversal in the "meeting-up of histories" (Massey 2005)! ${ }^{34}$ It is hard to completely dismiss this argument that most stories of asylum seeking are not only about fleeing 'from somewhere' but also seeking a place for a more secure future in different respects. However, this needs, on the one hand, to be connected with the argument that (im)mobilities of people are governed to the benefit of those already 'here' (subchapter 4.1; see also Feldman 2012, 82); and, on the other hand, there are histories and geographies connecting the spaces of flight and asylum seeking. Thus, I suggest that there are at least two stories to be told that are usually omitted with regards to asylum: a story of hidden "accumulation by dispossession" (Harvey 2003); and a story of spatial imaginations productive of a particular "moral geography" (Smith 2000).

First, the governing of asylum is considered as exterior to the relations of capitalist accumulation by dispossession (Harvey 2003) that have generated spatiotemporally highly unequal relations of wealth. And this exteriority constitutes arguably a crucial "anchorage of the relationships" (Foucault 1982, 791-92) of governing asylum. It is well illustrated by quote a former Federal Counsellor, Kaspar Villiger, who wrote a column titled "Migration - boon or bane?" in a large Swiss newspaper, "Economically successful states dispose of a combination of suitable economic, political, and social institutions as well as of a suitable culture of social norms and behaviours" (Villiger 2016). In his terms, the difference in wealth between countries (the main driver for migration to and the wealth of "economically successful states" such as Switzerland) is supposed to be explainable by institutions and culture alone.

34 It is ironically the same spatial imagination which allowed ancient colonialists to laud voyages of discovery that is informing alarmist discourses about 'voyages of flight' today (see Massey 2005, 4). 
Such a view denies any external relationship preceding the asylum procedures, but particularly the existence of a relationship between "our success" and "their failure" (see also Blomley 2011, 206). It negates historical relations of colonialism and imperialism as well as the "coloniality" (Grosfoguel 2008) of current global relations of accumulation and dispossession ${ }^{35}$ (Glassman 2006; Harvey 2003) and knowledge production ${ }^{36}$ (Santos 2014). It is on this exteriority that the asylum dispositif, its regime of access and case-making is based: It displaces structural violence as a cause for dislocation as being exterior to the claim (Barsky 1994, 146; Fassin 2011a). And it twists vulnerability in securitisation discourse as being located in the receiving societies vulnerable to foreigners' influx (Garelli and Tazzioli 2013, 1008-9).

Second, the governing of asylum ironically tends to reproduce the moral geographies by drawing upon a Western spatial imagination that not only removes structural violence from view but also locates political violence elsewhere. If structural violence is removed from consideration in applicants asylum claims, their subjection to political violence ${ }^{37}$ is what they need to account for in order to receive protection: "the body bears the truth of violence that the state looks for in order to grant them the status of refugee" (Fassin 2011a, 284). However, also political violence is displaced in the procedure, I suggest, as something of another place and concerning the Other, the "abject subject" (Butler 2011, xiii). In order to make their case as being persecuted 'at home', applicants are induced to denounce their societies (or nation-states) as defective, war-ridden, underdeveloped and corrupted. As spokespersons of the places they left behind, they (re)produce an image of disorder and failure 'elsewhere' which makes it possible to localise alterity

35 Switzerland, even though it never had colonies itself, was part and parcel of the colonialist circuits of accumulation and the cultural politics associated with colonialism (Purtschert, Lüthi, and Falk 2012). At present, it still is a crucial node in the worldwide trade in commodities (Erklärung von Bern 2011). Switzerland has moreover been successful in channelling huge flows of capital through its economy as a haven for tax evasion making it the infamous leader of the "financial secrecy index" (Tax Justice Network (TJN) 2016).

36 I acknowledge that my own knowledge production can be itself accused of furthering this coloniality - my own positionality in the coloniality of knowledge production has allowed me to do this laborious research and my theoretical and methodological approaches do not challenge "Eurocentric epistemologies" (Grosfoguel 2008, 20) but rather enact them.

37 To be sure, the bordering between structural and political violence is itself artificial and difficult to maintain as the two forms of violence are often intimately connected (Fassin 2011a, 294). 
abroad and sustain a moral geography of Western superiority (see also Smith 2000). Moreover, in assessments of applicants' credibility, experiences and ways of acting are regularly denounced as irrational or implausible by measuring them against our universalised Western standards and rendering them "abyssal knowledge and experiences" (Santos 2007). The displacement of political violence from the 'here and now' figures as a powerful alterity of the dispositif of governing asylum that needs to be acknowledged for its effects. 